\title{
USE OF MODIFIED CLAYS FOR THE REMOVAL AND DISPOSAL OF CIILORINATED DIOXINS AND OTHER PRIORITY POLLUTANTS FROM INDUSTRIAL WASTEWATERS.
}

\author{
Keeran R. Srinivasan and H. Scott Fogler \\ Deparment of chemical Enginecring \\ The University of Michigan \\ Ann Arbor, MI 48109.
}

\section{ABSTRACT:}

The dynamics of adsorption and elution of octachlorodibenzodioxin (OCDD) on modified clay adsorbents has been studied. In batch type experiments, a rapid approach to sorption equilibrium (within hours) as well as a Freudlich type sorption isotherm were noted. In packed bed sorption experiments using a step input of adsorbate concentration, no breakthrough was observed under a variety of volumetric flow rates suggesting multilayer adsorption of dioxins on modified clay sorbents. Elution of sorbed dioxin with carrier solvent tetrahydrofuran (THF) exhibited two peaks indicating heterogeneity of modified clay sorbents. Finally, successive sorption/elution/sorption experiments reveal that modified clay sorbents can be regenerated and reused.

\section{INTRODUCTION:}

Our previous work had clearly established that chemically modified clays are extremely suitable for efficient sorption of trace leveis of toxic organics such as PCDDs and other priority pollutants in wastewaterstreams $(1,4)$. Since ultimate destruction of these toxic organics is currently accepted as an environmentally desirable goal, a full scale development of wastewater treatment technology has to necessarily include an intermediate pre-concentration step. This is because the toxic organics are present at extremely low levels (low ppm to low ppt) in wastewater streams. This concept is explored graphically in Fig.1.

It is envisaged that the initial phase of any wastewater treatment technology would be a microseparation process in which cliry-balsed adsorbents would act as " molecular forceps " to remove the toxic organics in the input siream (STEP 1). The effluent stream can be reprocessed, if necessary, till an environmentally neutral water strean is obtained. The toxic organics sorbed on the modified clily sorbent can be further concentrated by elution in a carrier solvent with the concomitant regeneration of the sorbent for fut ther use (STEP) 2). At this point. pyrolysis of the toxic organics along will the carrier solvent may be considered as a viable opmon for the total destruction of the toxic organics. Alternatively, the sorben laden with the toxic organics can be direcily processed by any one of other detoxificatton techniques, typical examples of which are shown in the bottom of Fig 1 . Irespective of the method chosen for the destruction of the sorbed toxic organics, it is our belief that sorption of toxic organics has to be considered as the centerpiece of any successful wastewater treatment technology devoted specifically to the remediation of hazards posed by toxic organics at trace levels in wastewaters. 


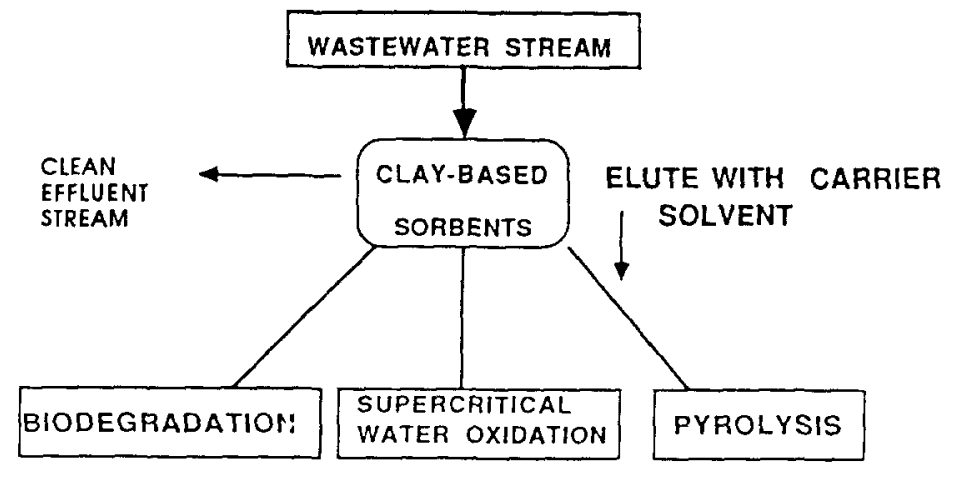

FIG. 1 SORPIION AND DESTRUCTION OF DIOXINS AND OTHER PRIORITY POLLUIANTS FROM WASTEWATERS USING CLAY-BASED ADSORBENIS.

It is for this reason that the development of efficient, and cost-effective adsorbents such as modified clays, the study of the sorbent structure in relation to its function, and the evaluation of the dynamics of the sorption/desorption processes have been the three areas of our current research effort, and in this paper, we report on the results of our study on the adsorption/desorption of octachlorodioxin (OCDD) on and from hydroxy aluminum montmorillonite (HYDALCLAY).

\section{METHODS AND MATERIALS:}

Montmorillonite, was obtained from Source Clay Minerals Repository, University of Missouri, Columbia,MO. Fractions having a mean particle size less than $1.0 \mu \mathrm{m}$ were converted to the Na form prior to use. Namontmorillonite, thus obiained (referred to in this paper as CLAY or unmodified clay) was cation-exchanged with hydroxy aluminum polymer in solution to form hydroxy aluminum montmorillonite (HYDAL-CLAY). Details are given elsewhere ${ }^{2}$. Conductivity-grade water available from a Milli-Q water system (Millipore Corporation; pH around 5.5) was filtered through a Nalgene $0.22 \mathrm{~mm}$ filtration unit prior to use. ${ }^{14} \mathrm{C}$ octachlorodibenzodiuxin (OCDD) of greater than $98 \%$ purity was obtained from Sigma Chemicals at a specific activity of $96 \mathrm{dpn} / \mathrm{ng}$. All other chemicals were of reagent grade and were used as received.

Rate of adsorption of OCDD to the sorbents used in this study was monitored in batch type sorption experiments at $25^{\circ} \mathrm{C}$ with vigorous mixing. At fixed time intervals, glass vials were centrifuged for 30 mins to separate and quantify the concentrations of OCDD in the two phases. Half way point of centrifugation, i.e. 15 minutes, were added to the measured times to correct for the possible contunation of sorption during centrifugation. Quicker phase separation using $0.22 \mu \mathrm{m}$ filters proved to be undiable due 10 nompecitic. and vatable binding of OCDD to the filer membranes. In all cases, the solution phase contaned 3000 ppm of ictrahndefuran (THF) and the matial concentration of OCDD was 3.0 Ipp. The rationate for the use of THF has becin descussed in one of our carlice publications 3 . The concentration of the sorbents wals $250 \mathrm{ppm}$. Each data point represents the mean of a sel of quadruplicates and the relative error of $10 \%$ represcnis the range of the actual experimental values from the calculated mean.

Equilibrium binding of OCDD to HYD $A$ L CLAY was siudied in a similar batch type configuration using initial concentrations of $O C D D$ in the range of $0.5-4.8 \mathrm{ppb}$, and 24 hrs. of equilibration time. All other experimental conditions and the operational procedures were the same as the ones described above. Control experiments without the sorbent were carried out concurrently to detemine the extent of nonspecific adsorption and was found to be less than 10 $\%$. Furthermore, the sedimented sorbent pellet was quantitatively transferred to a filter pad and counted to yield the "bound" value as a furker check and to obtain an overall mass balance of greater than $93 \%$. 
Adsorption/desorption of OCDD on CLAY and HYDAL-CLAY were carried out in an all-glass chromatographic column. Effluent samples were collected directly in scintillation vials and counted while the volumes collected were quantified by weight difference. Inerts in the form of quartz beads and glass wool were used as packing material to improve the hydraulic permeability of the packed beds containing clay sorbents. The weight ratio of the inerts to the sorbent was 10:1. Separate control experiments with the packing materials alone were also carried out. All experiments were carried out under constant pressure conditions and the flow rates were varied with two glass stoppers. Adsorption of OCDD was carried out using a step input value of $3.0-3.5 \mathrm{ng} / \mathrm{ml}$ and the volumetric fraction of the carrier solvent THF was increased to $3.0 \%$, which is 10 times its value in batch type experiments described above. Even though the presence of THF was expected to inhibit the binding of OCDD, it was felt that, unlike during the batch type experiments wherein vigorous mixing was employed, the higher amount of THF was deemed necessary to minimize nonspecific adsorption of OCDD on the inerts as well as on the clay sorbents during the flow through experiments on packed beds. The major focus of this study is to delineate the dynamics of OCDD sorption/desorption on HYDAL-CLAY, and therefore, nonspecific adsorption had to be kept to a minimum.

\section{RESULTS AND DISCUSSION:}

\section{Kinetics of Adsuiption:}

It hat been recognized that, by virtuc of the electrical charge on their respective surfaces, both unmodified clily and IIYDAL-CLAY (as verified by their respective zeta potentials of -27.0 and $+17.0 \mathrm{mV}$ for tie unmodified clity and HYDAL-CLAY5) adsorb water molecules which are then held by the surface as an adherent film, called hydrosphere ${ }^{6}$. Therefore, the major driving force for sorption of $O C D D$ on these two surfaces will be the extreme hydrophobicity of OCDD modified to some extent by the status of hydration of the two clay surfaces. In other words, physisorption is expected. It has been pointed out that adsorption takes place relatively fast in the case of physical adsorption?. This is generally the case, except when mass transfer processes such as film and intraparticle diffusion become significant, especially the latter 8 .

From Fig. 2, it can be seen that OCDD adsorption reaches a steady value within $2-4$ hrs, with most of the final value attained very rapidly, say within the first 30 minutes or so. The values of apparent monoliyer coverage are respectively 6.5 and $12.0 \mathrm{ng} / \mathrm{mg}$ for unmodified clay and HYDAL-CLAY. The rapid adsorption kinetics in the case of HYDAI-CLAY is surprising since this form of modified clay is known to exhibit " zeolite-like "properties 9 . Slow kinetics will be expected if the significant amount of surface area in the interlayer space of HYDAL-CLAY is involved in the binding of OCDD. Though our carlier studies with two isomeric forms of tetrachlorobiphenyls (TeCBs) raised this possibility 10 , our more recent results reveal that a greater proportion of OCDD may be bound on the external surfaces of HYDAL-CLAY"l. The rapid kinctics secn here will be in agreement with this latter observation. In the case of unnodified chay (Na-montmorillonitc), it disperses extensivcly in distilled water 12, which maly explain rapid mass transfer and guick adsorption on its surface. Similar rapid adsorption kinetics has been seen in the case of quinolitic adsorption on

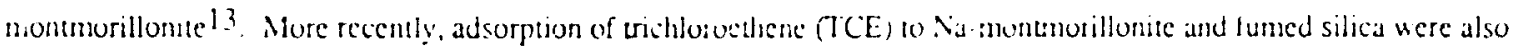
observed to be quite rapid ${ }^{4}$. Finally, it was noted that, with the separate control experments (i.e. in the absence of any surbent), anoum adsorbed to the glass was close to 15 ic of the mitial amount of OCDD added at shon time mterials which reduced to about $8 \%$ after 24 hrs. Therefore. 24 hr. equilibration period was chosen to determine the binding isothern of OCDD on IIYDAL-CLAY, the results of which are shown in Fig. 3.

\section{Binding Isolherm:}

The initial concentrations of OCDD used to obtain the isotherm $\left(25^{\circ} \mathrm{C}\right)$ shown in Fig. 3 ranged from $0.2-4.5$ $\mathrm{ng} / \mathrm{nL}$ and $3000 \mathrm{ppm}$ of THF was included in all solutions to minimize adsorption to glass, which was found to be around $8 \%$ of the initial amount of OCDD and the overall mass balance was $95 \%$ or better. OCDD bound to the sorbent was determined independently by filtration as mentioned in the Methods section. 
Clearly, OCDD binding to HYDAL-CLAY follows the so-called $S$ type adsorption isotherm curve ${ }^{15}$. This type of sorption behavior is demonstrated by molecules capable of moderate intermolecular attraction when binding on surface

FIG. 2 KINETICS OF ADSORPTION OF OCDD FIG. 3 BINDING OF OCDD TO HYDAL-CLAY: ISQTHIERM
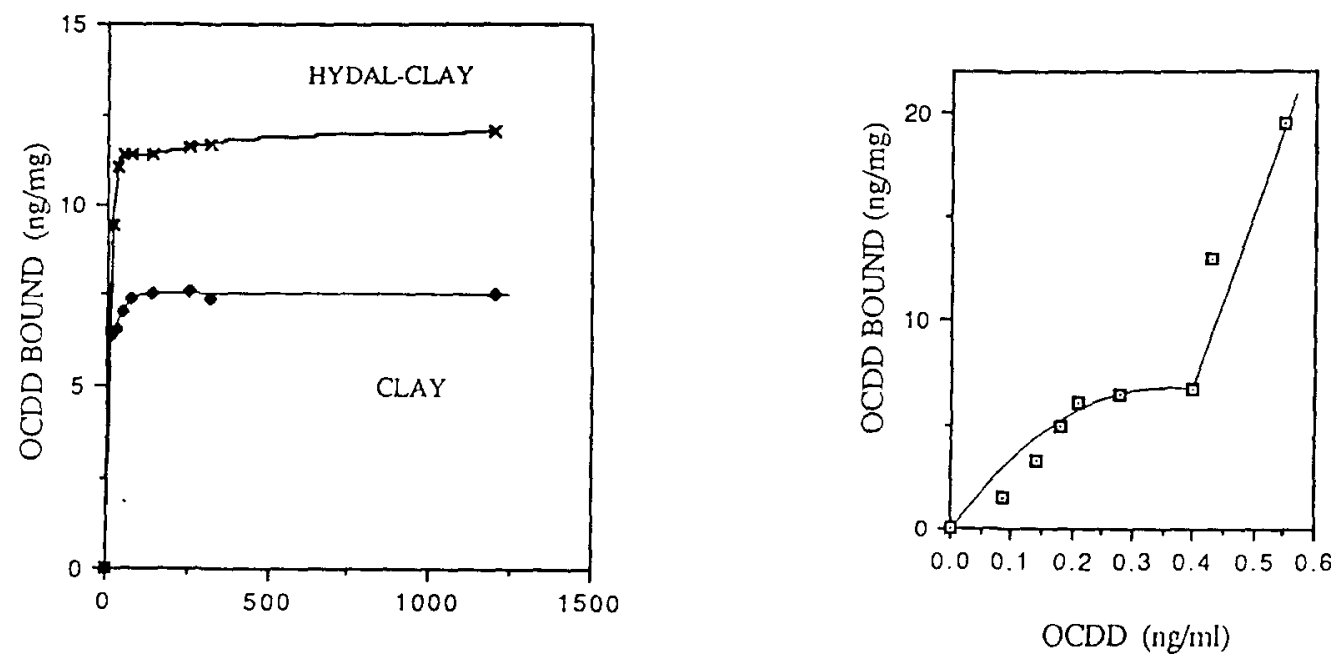

TIME (Min.)

sites to which solvent molecules can bind very strongly 15 . In other words, the weak initial adsorption of OCDD on a few surface sites promotes " cooperative adsorption " resulting in significant accumulation of OCDD on HYDAL-CLAY. Obviously, a similar situation does not occur with OCDD binding to Na-montmorillonite as shown by our previous work ${ }^{3}$. It is speculated that this may be related to the state of hydrated layer on HYDAL-CLAY as compared to unmodified clay. Finally, this weak binding of OCDD to unmodified clay is reflected in the dynamic sorption behavior of OCDD on a packed bed column of unmodified clay (more about this later).

The Freundlich equation, which is basically empirical but is often useful as a means of data reduction 16 , was applied to the data in Fig. 3 in the following form:

$$
\mathrm{qe}=\mathrm{KFC}^{1 / n}
$$

with qe and $C$ being respectively the surface bound and equilibrium concentrations of $O C D D . K F$ and $1 / n$ are constants for a given system. A log-log plot of $\mathrm{qe}_{\mathrm{e}} \mathrm{vs}$. $\mathrm{C}$, as shown in Fig. 4, was used to determine the constants in equation (1) and these are:

$$
\begin{aligned}
& \left.\left.K F=41.2 \text { in units of }(n g \text { OCDD })^{-1 / 3} \text { (mg. Solid }\right)^{-1} \text {. (ml. Solution }\right)^{+1.3} \mathrm{~J} \\
& \text { and } 1 / n=1.3
\end{aligned}
$$

It can be secn that the dala are well represented by a Freundlich type of isotherm. It has been recognized that Freundlich's type isotherm can be used to describe sorption data from dilute solutions 17 wherein the approximate equivalence of surface concentration of a solute and its surface excess allows for a formal derivation of Freundlich's equation from Gibbs adsorption equation 17 . It has also been pointed out that the constant, $1 / \mathrm{n}$, is inversely related to the difference between the free energy of a surface in contact with the solvent and the free energy of the same surface when covered with a monolayer of the sorbate ${ }^{17}$, and thus, a value of $1 / \mathrm{n}$ greater than unity represents unfavorable adsorption ${ }^{18}$. This agrees with the observed weak adsorption of OCDD on HYDAL-CLAY at low initial concentrations of OCDD followed by a strong binding at higher levels of the sorbate (Fig. 3).

There have been many reported instances of the applicability of equation (1) to sorption data, as for example, the binding of chlorinated biphenyls to illite clay ${ }^{19}$ and the sorption of Aroclor 1254 by kaolinite and montmorillonite 20 . The values of $\mathrm{KF}$ and $1 / \mathrm{n}$ obtained in this study are similar to the ones given in refs. 18 and 19 , and, in view of the phenomenological nature of the constants in Freudlich equation, any comparison should be considered to have only a limited value. 
III. PACKED BED EXPERIMENTS:

$\ln (\mathrm{BOUND})=3.72+1.3 * \ln \mathrm{C} ; \mathrm{R}=0.99$

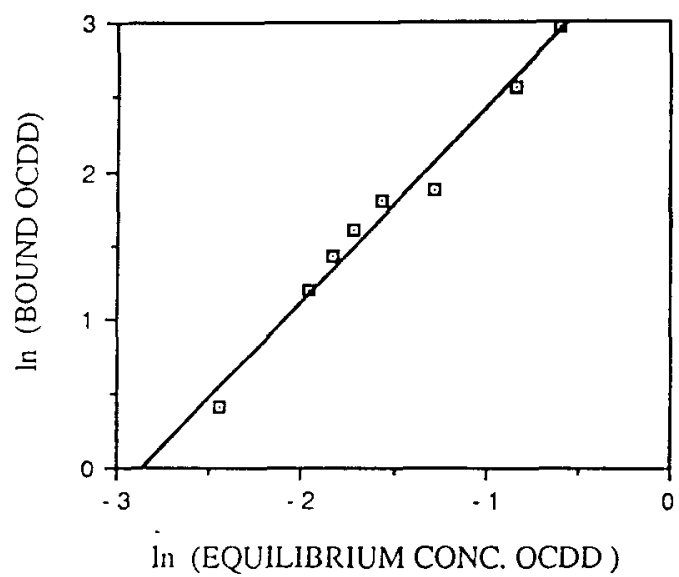

FIG. 5A BINDING OF OCDD TO UNMODIFIED CLAY

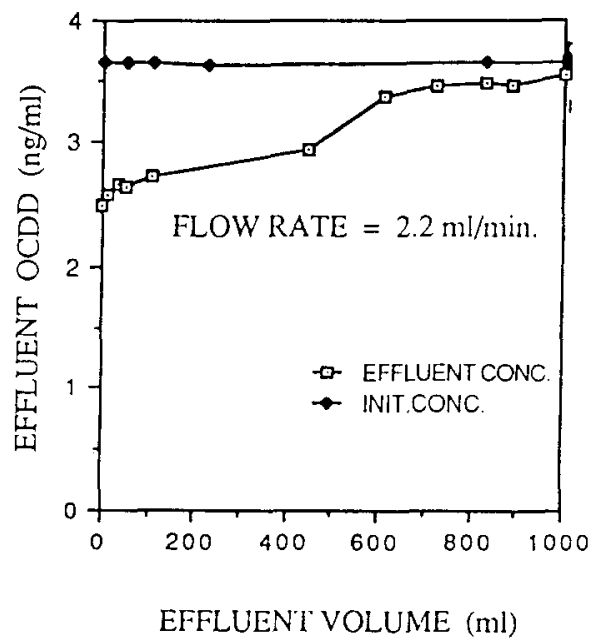

FIG. 4. FREUNDLICH PLOT OF OCDD BINDING TO HYDAL-CLAY

\section{A. SORPTION OF OCDD:}

The results of adsorption/desorption of OCDD on all-glass adsorption columns are shown in Fig. 5 - 10 . As explained before, the concentration of THF was raised to $3.0 \%$ by volume. Secondly, preliminary experiments revealed that sinall amounts of HYDAL-CLAY $(50 \mathrm{mg})$ intermixed with inerts such as quartz beads were the only practical way to obtain variable volumetric flow rates of $0.2-6.0 \mathrm{ml} / \mathrm{min}$ without applying too high a pressure. Control experiments with the inerts alone (results not shown) indicated that the amount of OCDD adsorbed on quartz beads was not significant.

The response of an initially sorbate free column to a step change in sorbate concentration at the column inlet (step input) is the well known breakthrough curve with a steady state effluent concentration equal to the step input. In fig. 5, it is seen that, with unmodified clay (Na-montmorillonite), such a breakthrough is obtained after $1000 \mathrm{ml}$ of OCDD solution at about $3.5 \mathrm{ng} / \mathrm{ml}$ is passed through the column indicating weak binding of OCDD to unmodified clay. The initual part of the effluent profile rises sharply and levels off slowly unil the breakthrough point is reached. Elution with step changes of 20 and $50 \%$ by volume THF (Fig. 5B) reveals a sharp desorption pulse following 50\% THF solution. Surprisingly, only a small amount of OCDD is eluted with $20 \%$ THF. The overall mass balance was $93 \%$. It is possible that the presence of $3.0 \%$ TIIF in the input OCDD solution may have been responsible for the weak binding and the observed breakthrough. It is important to realize that, other things being eyual, $3 \%$ THF in the inlct solution is sufficient to mimimize nonspecific adsorption to an extent that breaktlurough can be observed.

With HYDAL-CLAY (Figs. 6,8, and 9A), no such breakthrough is observed. At the lowest liow rate (Fig. 8). there is a considerable hold-up in the column, and this hold-up decreases with increasing fowrates (Figs. 6 and $9 A$ ). Qualitatively, this mily be related to a greater iesidence ime leading to higher surption at low flow rates. However, in order to obtain a better understanding of the dynamics of adsorption, the equilibrium adsorption data (Fig. 4) were used to calculate mean residence time for the solute, $\tau$, as follow's.

The entire adsorption process was assumed to be a simple, isothermal system with a single solute in an inert medium undergoing plug flow. The effect of the inerts (quarz beads) is neglected so that only a single mass transfer zone (i. e. between the bulk solution and the sorbent surface) is considered. Under these ideal conditions, it has leen shown that: 21 


$$
\tau=(\mathrm{L} / \mathrm{v})[1+(1-\varepsilon / \varepsilon)(\mathrm{dq} / \mathrm{dC}) \cdot(\mathrm{f})]
$$

Wilh

$$
L=\text { Length of the sorbent column }
$$

$v=$ Lineir velocity of solution flow

$\varepsilon=$ Column voidage $(0.4)$

$\mathrm{dg} / \mathrm{dC}=\mathrm{KF} \cdot(1 / \mathrm{n}) \cdot(\mathrm{C})\lfloor(1 / \mathrm{n})-1]$ from equation (1)

and $\quad \mathrm{f}=$ A conversion factor to dedimensionalize $\mathrm{d} \mathrm{g} / \mathrm{dC} \mathrm{tcm}$.

The results of above analysis at the inlet concentration OCDD of $3.5 \mathrm{ng} / \mathrm{ml}$ are shown in Table 1 . Also shown for comparison is the mean residence time assuming Langmuir type, fixed site adsorption in place of equation (1). To calculate the values given in column 4, equation (3) was combined with the following expression for $\mathrm{d} / \mathrm{dC}$ :

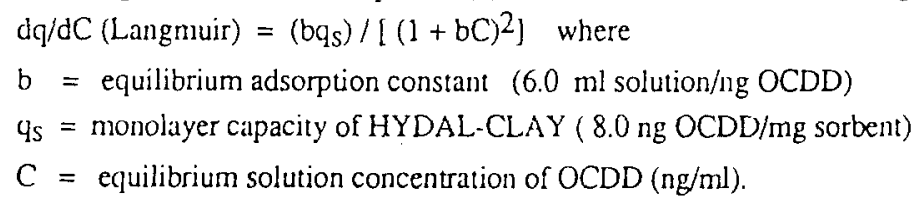

The values of monolayer capacity and the equilibrium adsorption constant were determined from the double reciprocal plot using the data upto the first plateau region of Fig. 3

\section{TABLE 1}

\section{MEAN RESIDENCE TIME FOR OCDD ON HYDAL-CLAY COLUMN}

$\begin{array}{ll}\text { Inlet OCDD Concentration } & =3.5 \mathrm{ng} / \mathrm{ml} \\ \text { Volume \% THF in inlet solution } & =3.0 \% \\ \text { Weight of HYDAL-CLAY used } & =50 \mathrm{mg} \\ \text { Colum Volume } & =7.1 \mathrm{ml}\end{array}$

\begin{tabular}{llccc}
\hline $\begin{array}{c}\text { Flow Rate } \\
(\mathrm{m} / \mathrm{min})\end{array}$ & $\begin{array}{c}\text { Linear Velocity } \\
(\mathrm{cm} / \mathrm{min})\end{array}$ & $\begin{array}{c}\tau \text { (Freundlich) } \\
(\mathrm{min})\end{array}$ & $\begin{array}{c}\tau \text { (Langmuir) } \\
\text { (min.) }\end{array}$ \\
\hline (1) & 6.0 & 3.4 & 404 & 16.0 \\
(2) & 2.2 & 1.24 & 1108 & 42.0 \\
\hline
\end{tabular}

\footnotetext{
* At this low flow rate, a narrower column was used.
}

Clearly, Freundlich type isutierm is a better representaten of scrption of OCDD on a packed bed of HYDAL-CLAY. The significant difference in the mean residence tumes calculated according to Freundhch sothem as opposed to Langmuir form of the isotherm may be understood in tcrms of mutulayer sorption process implicit in the former. It should be recognized that, due to a finite mass transfer resistance as well as the possibility of channeling due to the small size of the column used here, the actual breakthrough will occur even fuster than predicted by eçuation (3). Thus the absence of a breakthrough is surprising.

The fact that no breakthrough was observed could be attributed to not flowing sufficient quantity of the sorbate through the column. Therefore, a long term sorption experiment at a flow rate of $2.2 \mathrm{ml} / \mathrm{min}$ was carried out and the results are shown in Fig. 10. The arrow on the $x$ axis indicates the expected breakthrough point. The absence of breakthrough even in this case raises the possibility of an incipient phase separation of OCDD on HYDAL-CLAY column with the initially adsorbed $O C D D$ acting as nucleating sites. 
FIG. 5B. ELUTION OF OCDD WITH TETRAHYDROFURAN FIG.7.2nd ADSORPTION OF OCDD

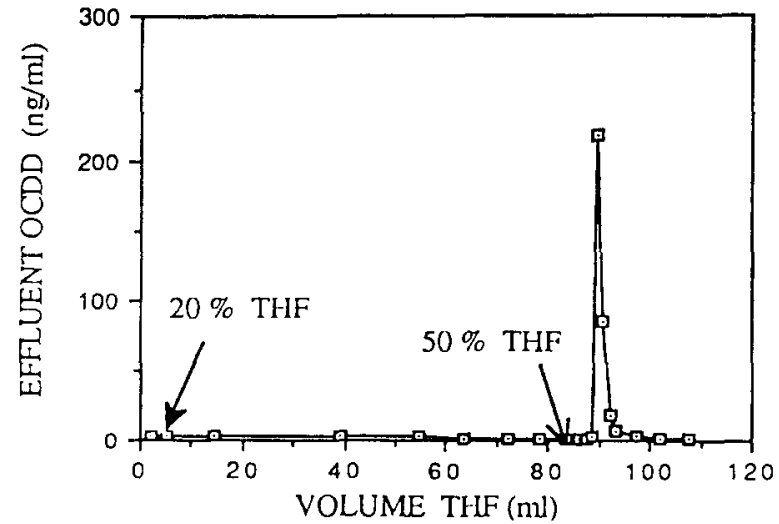

FIG. 6. ADSORPTION OF OCDD ON HYDAL-CLAY

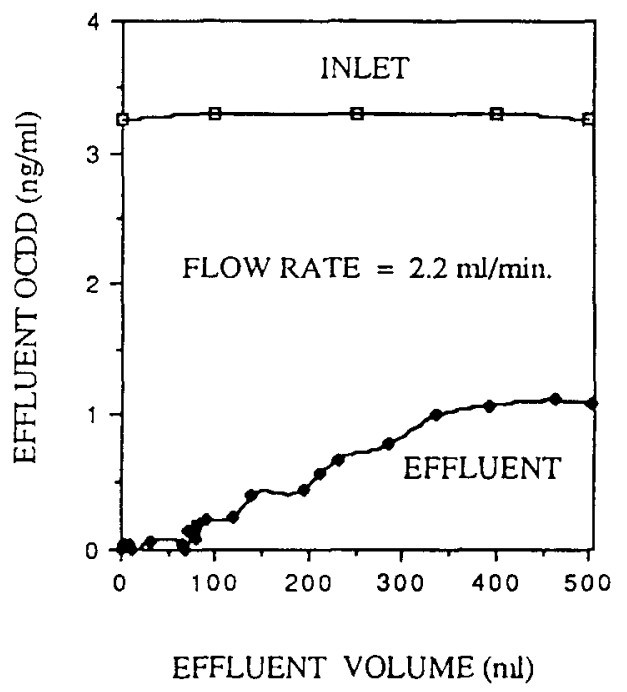

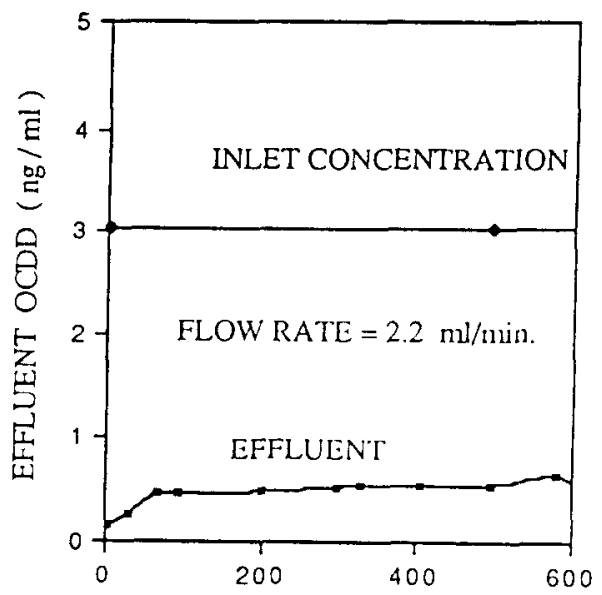

EFFLUENT VOLUME ( $\mathrm{ml})$

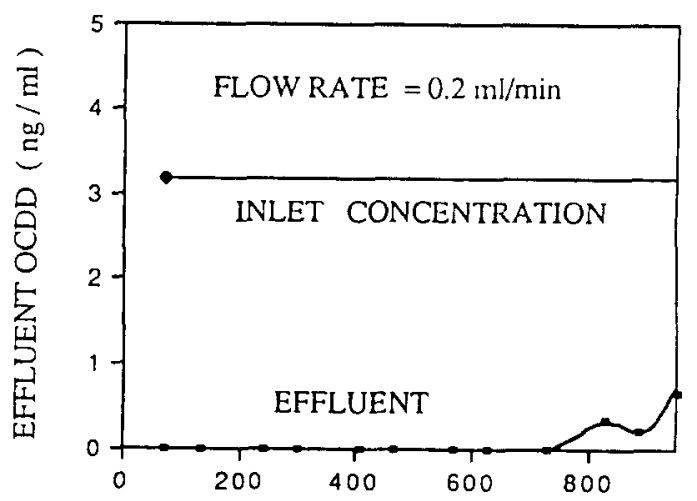

EFFLUENT VOLUME ( $\mathrm{ml})$ FIG. 8. OCDD ADSORPTION ON HYDAL-CLAY: LOW FLOW RATE

It has been suggested that, in a quiescent mediuin PCDDs may attach strongly to suspended solid containing organic matter and that filtration of these suspended particles could effectively alleviate the problem of dioxin contamination in wastewaters. In fact, such a procedure is currently being used to reduce 2,3,7,8-TCDD levels in process wastewaters 22 , and our results may be reconciled with above observations in the following manner. Following an initial layer of dioxin molecules on the organic carbon layer of the surface, further binding binding may be promoted by the extreme hydrophobicity of PCDDs leading to multilayer formation on the surface or a pscudo phase scparation.

Clearly, any future work has to be carried out at a much lower iniet concentration of OCDD so that sorption would be restricted to the initial flat region of the adsorption isotherm (Fig.3). This would require radiolabeled OCDD at a much higher specific activity and a future study is contemplated based on the availability of OCDD of high specific radioactivity.

\section{B. DESORPTION OF OCDD WITH THF:}

In most cases, desorption with THF was carried out at $20 \%$ and $50 \%$ THF in the eluting solution and as in the case of unmodified clay (Fig. 5B) bulk of the adsorbed OCDD was removed at $50 \%$ THF (figures not shown). However, as shown in Fig. 9B, a more complicated elution pattern with $20 \%, 33 \%$, and $50 \%$ THF was noted. As 
EIG. 2A. BINDING OF OCDD TOHYDAL-CLAX:HIGHFLOW RATE

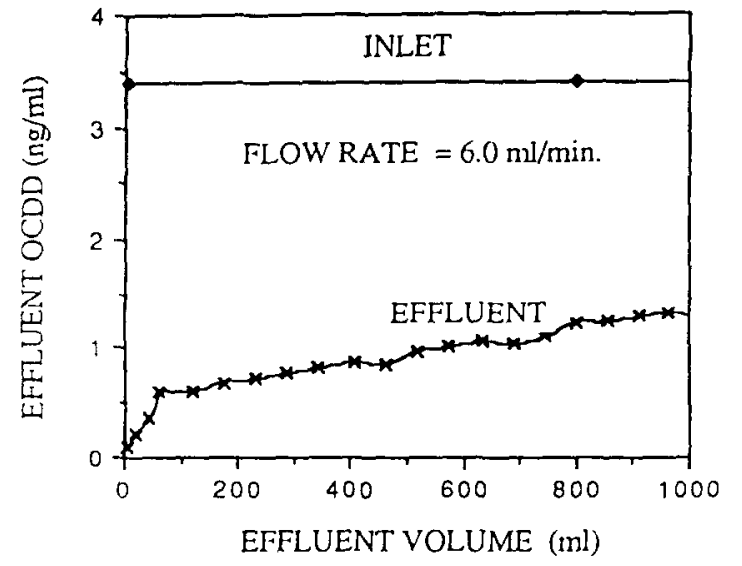

F1C.10 LONG TERM SORPTION OF OCDD ON HYDAL-CLAY

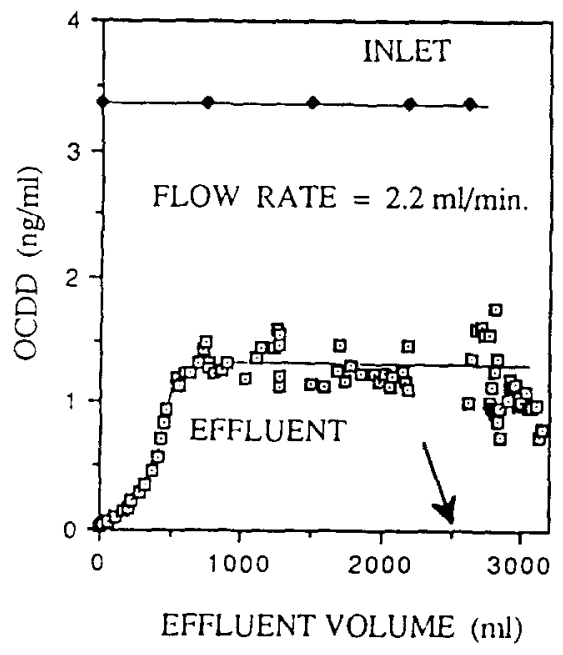

EIG. 9B. ELUTION OF SORBED OCDD WITH THF

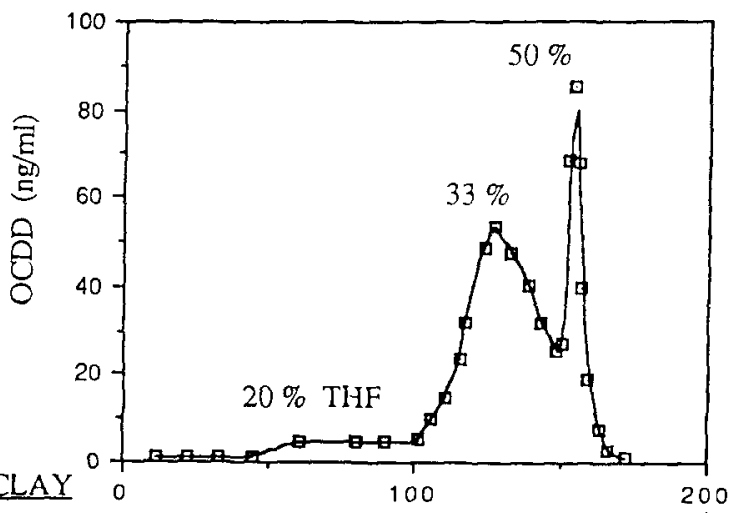

THF ELUANT VOLUME (ml)

before, only a small amount is eluted at $20 \%$ THF. But, two elution peaks are seen at $33 \%$ and $50 \%$ THF, and this is suggestive of heterogeneity of the OCDD binding process.

An earlier FTIR study of HYDAL-CLAY by us had revealed IR bands in the Oll stretching region correponding to hydroxy aluminum moiety as well as gibbsite which is a crystalline analog of precipitated aluminum lydroxide 4 . This comparison is shown in Table 2.

TABLE2

COMPARISON OF FTIR BANDSIN THE OH STKETCH REGIO

SPECIES

OH STRETCHING REGION BANDS

$\left(\mathrm{CM}^{-1}\right)$

IIYDAL-CLAY

$3395,3462,3526,3688$

HYDAL

3430 - 3460 (BROAD BAND)

GIBBSITE

$3395,3440,3520,3612$ 
Thus, two of the IR bands of HYDAL-CLAY, namely the ones at 3395 and the $3526\left(\mathrm{CM}^{-1}\right)$ seem to emerge from the gibbsite phase. Both these bands were sharp indicating that gibbsite phase was crystalline in nature. The other two bands ( 3462 and $3688\left(\mathrm{CM}^{-1}\right)$ originate from the hydroxy aluminum species. The band at $3688\left(\mathrm{CM}^{-1}\right)$ has been observed by us $^{2}$ as well as by earlier workers 23 . This band has been assigned to the $\mathrm{O}-\mathrm{H}---\mathrm{O}$ stretch of aluminum hydroxide ${ }^{24}$ and has been shown to be characteristic of polymeric hydroxy aluminum in the inter layer space of clay 23 . Thus, the two observed elution peaks are atuributable to two types of hydroxy aluminum on the clay surface. The ramifications of this finding will be explored in a later study.

\section{REGENERATION OF HYDAL-CLAY:}

The method of regeneration was to elute sorbed OCDD with $50 \%$ THF and follow this with an extensive wash with water to remove THF prior to using the same column for a 2 nd adsorption/desorption step. The results of adsorption of OCDD are compared at the same flow rate in Figs. 6, and 7. It can be seen that the HYDAL-CLAY column can almost be totally regenerated. However, the effluent $O C D D$ concentration during the 2 nd adsorption step is consistently higher, and this may be due to contamination from the previous step or insufficient washing with water following the first desorption-step. The question not yet addressed is, how many times can the HYDAL-CLAY column be reused, and secondly, what are the benefits of the regeneration process? Further reseatrch is indicated.

\section{CONCLUSIONS:}

(1) Rate of adsorption of OCDD on HYDAL-CLAY is quite rapid, and the sorption isotherm is of the Freundlich type.

(2) Packed bed sorption experiments with a step input of OCDD show that no breakthrough occurs suggesting multilayer sdsorption of OCDD on HYDAL-CLAY, or perhaps even the formation of a pseudo OCDD phase on pre-adsorbed OCDD molecules.

(3) Elution of sorbed OCDD with THF reveals that HYDAL-CLAY is heterogeneous with surface hydroxy aluminum as well as gibbsite phases.

(4) Preliminary results show HYDAL-CLAY can be regenerated.

\section{ACKNOWLEDGEMENTS:}

The above study was supported by grants from Environmental Protection $\Lambda$ gency (Grant No. R812555-010) and from The Department of Energy Pittsburgh Energy Technology Center(DOE/PETC Grant No. DE-FG22-87PC79918). The authors also acknowledge the assistance of Ms. Erika Sundstrom with the packed bed experinents.

\section{REFERENCES:}

(1) Srinivasan, Kecran, R., Fogler, H., Scolt, Gulari, E.,Nolan, T., F., and Schultz, J., S. : Environ. Progress, Vol. 4(4), 239 (1985).

(2) Srinivasin, Keeran R., and Fogler, H. Scou: " Removal of Trace Levels of 2,3,7,8 TCDD from Industrial Wastewaters by Sorption on Clay-based Sorbents: Pan I: Preparation and Charactcrization of Clay-based sorbents ", In "Chlorinated Dioxins and Dibenzofurans in Perspective (Eds.) C. Rappe, G. Choudhary, and L. H. Keith, Chapter 35, Lewis Publishers, Inc., Chelsea, MI., (1986)..

(3) Srinivisan, Keeran R., and Fogler, II. Scon: " Remuval of Tnace Levels of 2,3,7,8 TCDD from Industrial Wistewaters by Sorption on Clay-based Sorbents: Part 11: Binding of OCDD, 2,3,7.8 TCDD, and IICB to Clay-based sorbents ", In "Chlorinated Dioxins and Dibenzolurans in 
Perspective (Eds.) C. Rappe, G. Choudhary, and L. H. Kcith, Chapter 36, Lewis Publishcrs, Inc., Chelseal, MI., (1986).

(4) Fogler, H. Scott, and Srinivasan, Keeran R.: "Use of Clay-based Adsorbents for the Remuval of Chlorinated Dioxins and Biphenyls from industrial Wastewaters ", Proc. III World Congress of Chemical engineering, Tokyo, Japan; Vol.IIl, 623, (1986).

(5) Srinivasan, Keeran, R. and Fogler, H. Scott: "Use of Organo-clays in the Removal of toxic Organics from Industrial wastewaters: Effect of the Orientation of surface Organic Carbon ", Submitted for Publication to Environmental Progress.

(6) Worrall, W. E. : "Clays and Ceramic Raw Materials", Academic Press, London ( 1986).

(7) Goddard, E. D., and Somasundaran, P. : "Electrochemical Aspects of Adsorption on Mineral Oxides ", in Modern Aspects of Electrochemistry (Eds.) B. E. Conway, and J. O'M Bockris, Plenum Press, New York (1979).

(8) Wu, S., and Gschwend, P. M. : " Sorption Kinetics of Hydrophobic Organic Compounds to Natural Sediments and Soils ", Environ. Sci. Technol. 20, 717 (1986).

(9) Pinnavaia, T. J. : "Intercalated Clay Catalyst ", Science, 220, 365 (1983).

(10) Srinivasan, Keeran, R. and Fogler, H. Scott : "Sorption of Dioxins and Biphenyls on a Crosslinked Clay Adsorbent ", Presented at the Annual AlChE Meeting, Chicago, Inl. Nov., 1985.

(11) Nolan, T. F., Srinivasan, Keeran, R. and Fogler, H. Scott : Unpublished Results.

(12) Barrer, R. M. : " Zeolites and Clay Minerals as Sorbents and Molecular Sieves ", Academic Press, London, (1978).

(13) Heiny, A. K., de Bussetti, S. G., and Ferreiro, E. A. : " Adsorption of Quinoline fron açucous Solutions by Clays and Oxides ", Clays and Clay Minerals, 31, 29 (1983).

(14) Estes, Thomas, James . : "Adsorption of Low Molecular weight Halocarbons from water by Mineral Oxide surfaccs", Ph. D. Thesis, University of California at Los Angelos, USA ( 1987)

(15) Giles, C. H., MacEwan, T. H., Nakhwa, S. N., and Smith, D. : J. Chem. Soc. (London), 3973 (1960).

(16) Weber, W. J. Jr. : "Physico-Chemical Processes for Water Quality", Wiley -Interscience, New York, p.211 (1972).

(17) Kipling, J. J. : "Adsorption from Solutions of Non-Electrolytes ", Academic Press, London (1965).

(18) Voice, T. C., Weber, W. J., Jr. : "Sorption of Hydrophobic Compounds by Sediments, Soils, and Suspended Solids - I ", Water Research, 17 1433 (1983).

(19) Haque, R. and Schmedding. D. : "Studies on the Adsorption of Selected Polychlorinated Biphenyl Isomers on Several Surfices", J. Environ. Sci. Heallh, B1122, 129 (1976).

(20) Weber, W. J., J., Voice, T. C., Pirbazari, M., Hunt, G. E., and Ulanoff, D. M. : "Sorption of Ilydrophobic Compounds by Sedinents, Soils, and Suspended Solids - 11 ", Water Rescarch, 17 1433 (1983).

(21) Ruthven, Douglas, M. : " Principles of Adsorption and Adserption Processes ". Wiley-Interscience, New York,p.227 (1984).

(22) Robbins, Lanny: Private Communication, Dow Chemical Company, Mlidland, MI. (1985).

(23) Brydon, J. E., and Kodama, H.: "The Nature of Aluminum Hydroxide-Montmorillonite Complexes ". The American Mineralogist. 51, 875 (1966).

(24) Nakamoto, K., Margoshes, M., and Rundle, R. E. : " Suretching Frequencies as a Function of Distance of Hydrogen Bonds ", J. Amer. Chem. Soc. 77, 6480 (1955). 